\title{
Single-step preparation of topological gels using vinyl-modified $\beta$ - cyclodextrin as a figure-of-six cross-linker
}

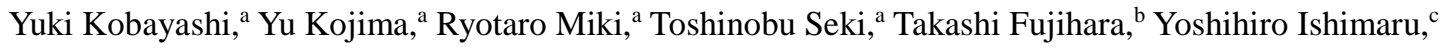 \\ Yuya Egawa*a \\ a. Faculty of Pharmacy and Pharmaceutical Sciences, Josai University, 1-1 Keyakidai, Sakado, Saitama \\ 350-0295, Japan \\ b. Research and Development Bureau, Comprehensive Analysis Center for Science, Saitama University, \\ Shimo-ohkubo 255, Sakura-ku, Saitama, Saitama 338-8570, Japan \\ c. Division of Material Science, Graduate School of Science and Engineering, Saitama University, 255 \\ Shimo-ohkubo, Sakura-ku, Saitama, Saitama 338-8570, Japan
}

\begin{abstract}
Herein, we have proposed a single-step preparation of topological gels using vinyl-modified $\beta$ cyclodextrin (V- $\beta-\mathrm{CyD})$ and isoprene. Copolymerization of $\mathrm{V}-\beta-\mathrm{CyD}$ and isoprene in an aqueous solution resulted in gelation due to $\mathrm{V}-\beta-\mathrm{CyD}$ acting as a novel type of copolymer chain cross-linker. The vinyl moiety of V- $\beta$-CyD becomes a part of the copolymer, while the $\beta$-CyD moiety of V- $\beta$-CyD simultaneously incorporates the isoprene component of the copolymer. V- $\beta-\mathrm{CyD}$ is capable of two different modes of cross-linking at each end, i.e., chemically bonding and mechanically interlocking. Due to the shape of the cross-linking point, we refer to it as figure-of-six cross-linking. Nuclear magnetic resonance (NMR) analysis showed that the gel contained V- $\beta-C y D$ and isoprene in an approximately 1:0.3 stoichiometry. The relatively high content of $\beta$-CyD was reflected in the character of the gel; the gel swelled in dimethylformamide (DMF) which is a good solvent of $\beta$-CyD. A fluorometric analysis using 6-(p-toluidino)-2-naphthalenesulfonic acid (TNS) showed that the appended $\beta$-CyD was able to accommodate guest molecules. Introduction of an additional vinyl monomer into the gel was also successful. Addition of 4-vinylphenylboronic acid to the preparation procedure yielded a sugar-responsive gel that swelled in the presence of D-fructose.
\end{abstract}

\section{Keywords}

Cyclodextrin, phenylboronic acid, topological gel, cross-link, copolymer 


\section{Introduction}

Cyclodextrins (CyDs) are a series of oligosaccharides that are widely known as host molecules in supramolecular chemistry [1-3]. CyDs accommodate many types of guest molecules because the CyD cavity interior wall is composed of $\mathrm{C}-\mathrm{C}$ and $\mathrm{C}-\mathrm{O}$ bonds. CyD guest molecules include both low molecular weight compounds and polymers. Recently, inclusion complexes of CyDs and polymers have attracted substantial attention in the field of material chemistry due to their special character derived from their unique structures $[4,5]$. One of the notable applications of CyD polymer complexes is in topological gels developed by Ito's group [6-8]. These topological gels are prepared in three steps. The first step is the preparation of a complex between a polymer and CyDs, termed pseudopolyrotaxane. In the second step, each terminal of the pseudopolyrotaxane is modified with bulky stoppers to keep the CyDs on the polymer axis, resulting in a structure referred to as a polyrotaxane. In the final step, the polyrotaxane is cross-linked with a suitable cross-linker through a chemical reaction between the CyD hydroxyl groups within the polyrotaxane. As an example [6], diamino-terminated poly(ethylene glycol) (amino-PEG) and $\alpha$-CyD were used to form a pseudopolyrotaxane. The amino terminals of the pseudopolyrotaxane were modified with $\mathrm{m}$ dinitrophenyl groups as stoppers to prepare a polyrotaxane. Finally, the polyrotaxane was crosslinked with cyanuric chloride. In the final structure of the obtained topological gels, polyrotaxane chains are cross-linked with a figure-of-eight cross-linker comprising two connected CyD rings.

In 2016, the Wenz group reported a two-step preparation method for topological gels [9]. They prepared polyrotaxane in a single step by simultaneous free radical polymerization of isoprene and styrene in the presence of methylated $\beta$-CyD. In the obtained polyrotaxane, the isoprene components of the copolymer were covered with methylated $\beta-\mathrm{CyD}$, and the styrene components of the copolymer acted as a stopper to avoid dethreading of the methylated $\beta$-CyD. They have described this type of polymerization as rotaxa-polymerization [9-11]. Additionally, they demonstrated the applicability of many kinds of vinyl monomers and CyD derivatives in rotaxa-polymerization and showed a broad lineup of polyrotaxanes. As an application of rotaxa-polymerization, they prepared a topological gel in two steps. In the first step, they prepared a polyrotaxane composed of isoprene, styrene, and methylated $\beta$-CyD. In the second step, hexamethylene diisocyanate was used to cross-link the residual hydroxyl groups of the methylated $\beta$-CyD of polyrotaxane [9].

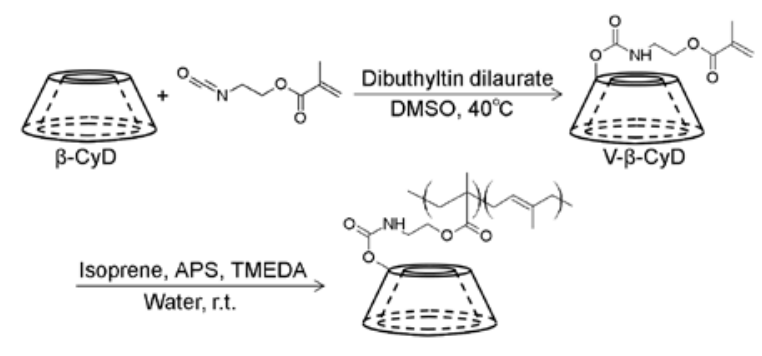


Scheme 1 Reaction scheme of V- $\beta-C y D$ and copolymerization of V- $\beta-C y D$ and isoprene.

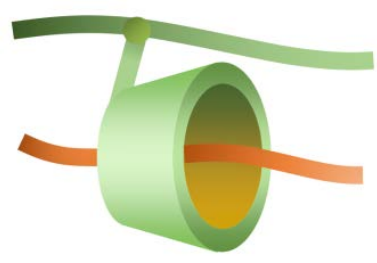

Fig. 1 Conceptual illustration of figure-of-six cross-linking.

In this report, we have attempted to prepare topological gels in a single-step fashion using simultaneous free radical polymerization of isoprene and vinyl modified $\beta-\mathrm{CyD}(\mathrm{V}-\beta-\mathrm{CyD})$ (Scheme 1 ). We expected that the obtained copolymer would append $\beta-C y D$ moieties, and that the appended $\beta$ CyD can include another copolymer chain because the polyisoprene component acts as a guest for $\beta$ CyD [9-12]. In the expected structure (Fig. 1), two copolymer chains are cross-linked by V- $\beta$-CyD. On one side of the cross-link, the vinyl moiety of V- $\beta$-CyD constitutes a portion of the copolymer chain. On the other side, the $\beta$-CyD moiety includes another copolymer chain. The shape of this crosslinking mode led us to call it a figure-of-six cross-link. At the same time, the V- $\beta$-CyD component acts as a stopper for V- $\beta$-CyD. The expected structure contains all elements required for topological gels; i.e., a polymer chain, an interlocked cross-link, and a stopper.

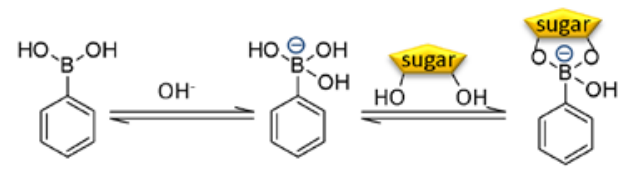

Scheme 2 Acid-base equilibrium of PBA and equilibrium between PBA and sugar.

Additionally, we attempted to incorporate functionality into the gel. To obtain a sugar response, phenylboronic acid was introduced as a component of the copolymer. It is widely known that phenylboronic acid derivatives react with the diol moiety of sugars to form a cyclic ester (Scheme 2). This feature is expected to apply to sugar sensors and drug delivery systems related to diabetes [1315]. We copolymerized 4-vinylphenylboronic acid, isoprene, and V- $\beta$-CyD to obtain a gel and investigated its sugar response.

\section{Material and methods}

\section{Materials}

$\beta$-CyD was purchased from Junsei Chemical Co. Ltd. (Tokyo, Japan). Isoprene (stabilized with 4-tert- 
butylcatechol: TBC), dibutyltin dilaurate, 2,6-di-tert-butyl-p-cresol, and 4-vinylphenylboronic acid (containing varying amounts of anhydride) were obtained from Tokyo Chemical Industry Co., Ltd. (Tokyo, Japan). Ammonium peroxodisulfate (APS), 2-isocyanatoethyl methacrylate, and $N, N, N^{\prime}, N^{\prime}$ tetramethylethylenediamine (TMEDA) were obtained from Wako Pure Chemical Industries Ltd. (Osaka, Japan). Polyisoprene (99+\% trans-1,4) and 4-(2-hydroxyethyl)-1-piperazineethanesulfonic acid (HEPES) were purchased from Sigma-Aldrich Japan (Tokyo, Japan), and 6-(p-Toluidino)-2naphthalenesulfonic acid (TNS) was purchased from Cosmo Bio Co. Ltd. (Tokyo, Japan). Isoprene was purified via distillation to remove the polymerization-inhibitor TBC. Other chemicals were used without further purification.

\section{Preparation of V- $\beta$-CyD}

$\beta$-CyD (5.67 g, $5.00 \mathrm{mmol}$, dried in vacuo) and dibutyltin dilaurate ( $95.2 \mu \mathrm{L}, 160 \mu \mathrm{mol})$ were dissolved in $100 \mathrm{~mL}$ DMSO (dehydrated) at $40^{\circ} \mathrm{C}$. Separately, 2-isocyanatoethyl methacrylate ( $846 \mu \mathrm{L}, 6.00$ $\mathrm{mmol}$ ) was dissolved in $30 \mathrm{~mL}$ DMSO (dehydrated) and was added dropwise to the solution of $\beta$-CyD and dibutyltin dilaurate. The reaction was monitored using silica gel thin-layer chromatography with $n$-butanol/EtOH/water (5/4/3, v/v/v) as a development solvent, and $\beta$-CyD derivatives were detected with anisaldehyde as the detecting agent. Upon the appearance of di-modified $\beta$-CyD (22 h), the reaction solution was concentrated under reduced pressure and was poured into acetone (500 mL). The resulting precipitate was purified via chromatography using a highly porous polystyrene gel (DiaionHP-20, Mitsubishi Chemical, Tokyo, Japan) and was eluted with a 15\% aqueous methanol solution. As a polymerization inhibitor, 2,6-di-tert-butyl-p-cresol was added to the eluent at a concentration of approximately $3 \mathrm{ppm}$. The fraction containing only the mono-modified derivative was collected and evaporated. The concentrated solution (50 mL) was poured into acetone (500 mL). In this process, 2,6-di-tert-butyl-p-cresol was dissolved in acetone. The resulting white precipitate was collected using a glass filter, was washed with a small amount of acetone thrice, and was dried in vacuo (1.17 g, 20.6\%).

${ }^{1} \mathrm{H}$ NMR (400 MHz, DMSO-d 6 , Fig. S1): $\delta 7.19$ (t, 1H, NH), $\delta 6.08\left(\mathrm{~s}, 1 \mathrm{H}, \mathrm{C}=\mathrm{CH}_{2}\right), \delta 5.89(\mathrm{~s}, 1 \mathrm{H}$, $\mathrm{C}=\mathrm{CH}_{2}$ ), $\delta$ 5.82-5.56 (m, 13H, CyD OH-2, OH-3), $\delta 4.87$ (m, 7H, CyD H-1), $\delta 4.62-3.79$ (others), $\delta$ 3.76-3.47 (m, 28H, CyD H-3, H-5, H-6), $\delta 3.45-3.11$ (m, 62H, CyD H-2, H-4, water), $\delta 1.87$ (s, 3H, $\mathrm{CH}_{3}$ ). MS (FAB, positive mode, matrix: 3-NBA, Fig. S2) $\mathrm{m} / \mathrm{z}: 1312.4$ (expected $\mathrm{m} / \mathrm{z}$ of $[\mathrm{M}+\mathrm{Na}]^{+}$: 1312.4). Elemental analysis, calculated for $\mathrm{C}_{49} \mathrm{H}_{79} \mathrm{NO}_{38}\left[\mathrm{~V}-\beta-\mathrm{CyD} \cdot 7 \mathrm{H}_{2} \mathrm{O}\right]: \mathrm{C} 41.56$, H 6.62, N 0.99\%, found: C 41.73, H 6.24, N 1.22\%.

\section{Preparation of gel}

V- $\beta$-CyD (90.0 mg, $69.8 \mu \mathrm{mol})$ and APS $(325 \mu \mathrm{g}, 1.50 \mu \mathrm{mol})$ were dissolved in water $(500 \mu \mathrm{L})$ in the $9.75 \mathrm{~mm}$ diameter well of a microtiter plate (48 well), and the solution was purged with 
$\mathrm{N}_{2}$ for $20 \mathrm{~min}$. Isoprene $(22.5 \mu \mathrm{L}, 225 \mu \mathrm{mol})$ was then added to the solution, which was gently shaken for $20 \mathrm{~min}$. TMEDA $(1.04 \mu \mathrm{L}, 5.00 \mu \mathrm{mol})$ was subsequently added to initiate the polymerization process. After $24 \mathrm{~h}$, the polymerized gel was removed from the well, immersed in $30 \mathrm{~mL}$ of water and washed for $12 \mathrm{~h}$. This process was repeated thrice, with water replacement occurring every $12 \mathrm{~h}$.

In a similar manner, a gel containing phenylboronic acid was prepared. V- $\beta$-CyD (90.0 mg, $69.8 \mu \mathrm{mol})$, APS (325 $\mu \mathrm{g}, 1.50 \mu \mathrm{mol})$, and 4-vinylphenylboronic acid (1.1 mg, $7.5 \mu \mathrm{mol}$ ) were dissolved in water $(500 \mu \mathrm{L})$ in the microtiter plate well. The same procedure was used to prepare the gel.

\section{Swelling test}

The water-washed gel was immersed in each solvent, and the weight of the gel was measured over time. Upon reaching a constant weight, the weight was recorded as a swollen gel ( $\left.W_{\text {swollen }}\right)$, and the gel was removed to another solvent. The order of solvents used was water, DMF, THF, and $\mathrm{MeOH}$. After recording the $W_{\text {swollen }}$ values, the gel was washed by immersing in water for $12 \mathrm{~h}$, with water replacement (thrice) occurring every $12 \mathrm{~h}$. The gel was then dried under vacuum at $40^{\circ} \mathrm{C}$ for $12 \mathrm{~h}$ after which the weight of the dried gel $\left(W_{\text {dry }}\right)$ was measured. The ratio of $\left(W_{\text {swollen }} / W_{\text {dry }}-1\right) \times 100(\%)$ was defined as the value of swelling degree.

\section{Sugar response test}

The water-washed gel was immersed in a buffer solution (10 mM HEPES, pH 7.4) for $24 \mathrm{~h}$ and the gel weight was measured. After that, the gel was removed to a buffer solution containing $100 \mathrm{mM}$ D-fructose (10 mM HEPES, $\mathrm{pH}$ 7.4) for $48 \mathrm{~h}$ and the weight of the gel was measured. This procedure was repeated thrice. After that, the gel was treated with the same water washing and drying procedure described above to calculate the swelling degree.

\section{Results and Discussion}

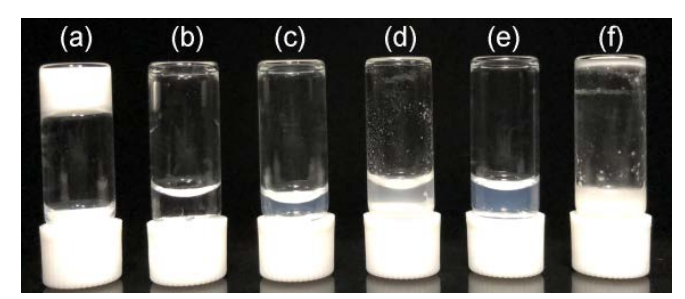

Fig. 2 Photographs of vials inverted after polymerization: (a) polymerized with V- $\beta$-CyD $(69.8 \mu \mathrm{mol})$ and isoprene ( $225 \mu \mathrm{mol})$; (b) polymerized with isoprene (225 $\mu \mathrm{mol})$; (c) polymerized with V- $\beta$-CyD (69.8 $\mu \mathrm{mol})$; (d) polymerized with native $\beta$-CyD (69.8 $\mu \mathrm{mol})$ and isoprene $(225 \mu \mathrm{mol})$; (e) polymerized with methylated $\beta$-CyD (69.8 $\mu \mathrm{mol})$ and isoprene (225 $\mu \mathrm{mol})$; (f) polymerized with V- $\beta$ - 
CyD $(69.8 \mu \mathrm{mol})$ and isoprene $(225 \mu \mathrm{mol})$ in the presence of 1-aminoadamantane $(69.8 \mu \mathrm{mol})$.

\section{Preparation of the topological gel}

Copolymerization of V- $\beta-C y D$ and isoprene produced a white cloudy gel. The white gel did not show fluidity, and it did not separate from the vial bottom upon inversion of the vial (Fig. 2a). The white color is derived from Mie scattering, which suggests the existence of aggregated clusters whose size is close to or larger than the wavelengths of visible light.

To confirm the importance of $\mathrm{V}-\beta-\mathrm{CyD}$ on gelation, we conducted several comparative experiments. The sole use of isoprene or $\mathrm{V}-\beta-\mathrm{CyD}$ did not promote gelation (Fig. 2b, c). When isoprene was polymerized in the presence of native $\beta$-CyD or methylated- $\beta$-CyD, some precipitates formed, which were assumed to be a pseudopolyrotaxane comprising polyisoprene and each $\beta$-CyD derivative (Fig. 2d, e); however, gelation was not achieved. These comparative experiments demonstrated that both isoprene and V- $\beta$-CyD were essential for gelation.

Additionally, we carried out the polymerization process in the presence of 1-adamantanamine which is known to be a strong guest for the $\beta$-CyD cavity [16]. The coexistence of 1-adamantanamine inhibited the gelation process (Fig. 2f), strongly suggesting that inclusion of the isoprene component by $\beta$-CyD is needed in the gelation process.

\section{Swelling test}

Following the polymerization step, the gel was white; however, the gel became transparent when immersed in a sufficient volume of water. The swelling degree of the gel was $1650 \%$ in water (Table 1). When DMF was used as a solvent, the swelling degree dramatically increased to $3820 \%$. Although the gel was soft in DMF, it did not dissolve or disintegrate. Subsequent experiments revealed that the swelling value decreased in THF (1520\%) and $\mathrm{MeOH}$ (920\%).

In consideration of the swelling tests, we checked the solubility of the gel components (Fig. 3). trans-Polyisoprene was used as a model component because Wenz group reported that transpolyisoprene was the main component of polyrotaxane prepared with isoprene and methylated $\beta$-CyD in rotaxa-polymerization [9]. Fig. 3 (a) contains a picture of $\beta$-CyD (270 mg) in each solvent (10 mL) and indicates that DMF is a good solvent. Water is intermediate, and $\mathrm{MeOH}$ and THF are poor solvents for $\beta$-CyD. Fig. 3 (b) shows that THF is the only good solvent for trans-polyisoprene, while water, DMF, and $\mathrm{MeOH}$ are poor solvents.

Table 1 Swelling degree of the gel composed of V- $\beta-C y D$ and isoprene and solubility of $\beta-C y D$ and trans-polyisoprene. 


\begin{tabular}{cccc}
\hline Solvent & $\begin{array}{c}\text { Swelling degree } \\
\text { of gel (\%) }\end{array}$ & $\begin{array}{c}\text { Solubility of } \beta- \\
\text { CyD }\end{array}$ & $\begin{array}{c}\text { Solubility of trans- } \\
\text { polyisoprene }\end{array}$ \\
\hline Water & 1650 & Intermediate & Poor \\
DMF & 3820 & Good & Poor \\
THF & 1520 & Poor & Good \\
MeOH & 920 & Poor & Poor \\
\hline (a) B-CYD & &
\end{tabular}

Fig. 3 Solubility of gel components in solvents. Red circles indicate the phase separation component. (a) $\beta$-CyD (270 mg) in $10 \mathrm{~mL}$ of each solvent: (b) trans-polyisoprene (a pellet: 324-351 mg) in $40 \mathrm{~mL}$ of each solvent.

Table 1 summarizes the results of the swelling and solubility tests, indicating that the swelling degree is related to solubility for $\beta$-CyD. In contrast, the solubility for trans-polyisoprene is not reflected in the swelling degree. THF is the only good solvent for trans-polyisoprene; however, the swelling degree of the gel was relatively low. These results suggest that the gel contains a relatively high content of the $\beta$-CyD moiety.

\section{Investigation of the gel structure}

To investigate the gel components, we utilized nuclear magnetic resonance (NMR) analysis. To enable solid-state NMR analysis, the prepared gel was dried in vacuo and ground with a mortar and pestle. The solid-state ${ }^{13} \mathrm{C}$ CP/MAS NMR spectrum of V- $\beta$-CyD revealed a signal at $160-170 \mathrm{ppm}$ derived from the carbonyl carbon of unpolymerized methacrylate (Fig. S3). In the NMR spectrum of the ground gel (Fig. S4), that signal disappeared, and a new signal was observed at around $180 \mathrm{ppm}$, suggesting that the polymerization of the vinyl group was successful [17]. As shown in Fig. S4, a 
broad peak at 10-30 ppm may suggest the existence of polyisoprene [18]; however, this was unclear. To analyze the relative stoichiometry of $\mathrm{V}-\beta-\mathrm{CyD}$ and isoprene, solution state ${ }^{1} \mathrm{H}$ NMR was implemented using dissolved gel. To dissolve the gel, it was immersed in $1 \mathrm{M} \mathrm{NaOH}$ at $60^{\circ} \mathrm{C}$ for several days to hydrolyze the ester bond connected to the $\beta$-CyD moiety. After confirming complete dissolution, the solution was neutralized with $1 \mathrm{M} \mathrm{HCl}$, and the solution was evaporated. The residue was then dissolved in $\mathrm{D}_{2} \mathrm{O}$ and subjected to solution state ${ }^{1} \mathrm{H}$ NMR. The upfield range of 0.3-2.4 ppm in the ${ }^{1} \mathrm{H}$ NMR spectrum (Fig. S5) represented the copolymer chain composed of the V- $\beta$-CyD methacrylate moiety and isoprene. When integration of the peak at $5.1 \mathrm{ppm}(\mathrm{CyD} \mathrm{H}-1)$ was set to 7.0, the integration of the $0.3-2.4 \mathrm{ppm}$ range was calculated to be 7.1. This value of 7.1 includes 5.0 protons derived from polymethacrylate $\left(\mathrm{CH}_{2}\right.$ and $\left.\mathrm{CH}_{3}\right)$ because V- $\beta$-CyD contains $\beta$-CyD and methacrylate in a 1:1 ratio. Thus, the residual value of 2.1 protons stems from polyisoprene. Since two methylene groups $(4 \mathrm{H})$ and a methyl group $(3 \mathrm{H})$ of polyisoprene show chemical shifts in this range, the molar ratio of $\mathrm{V}-\beta-\mathrm{CyD}$ to isoprene was calculated to be 1:0.3 in the prepared gel, which means that $\beta$-CyD constitutes $87 \mathrm{wt} \%$ of the prepared gel. The calculated molar ratio 1:0.3 differed from the charge ratio of $\mathrm{V}-\beta-\mathrm{CyD}$ to isoprene, which was 1:3. We also tried to prepare the gel with a charge ratio of $1: 1$, but gelation was not observed. Although the reason is not well understood, these experiments suggest that the stoichiometry of V- $\beta$-CyD and isoprene are important.

The gel was applied for elemental analysis, and the found values were C 43.62, H 6.75, and $\mathrm{N}$ $1.52 \%$. If the gel is polymerized in charge ratio ( $\mathrm{V}-\beta-\mathrm{CyD}$ :isoprene $=1: 3)$, the calculated values are C 51.43, H 6.95, and N 0.94\%. The relatively small value of $C$ found with the prepared gel suggests that the amount of isoprene polymerized into the gel is relatively small. However, it was difficult to calculate a distinct molar ratio due to the existence of containing water in the prepared gel. Additionally, the value of $\mathrm{N}$ is varied by a small amount of residual TMEDA in the gel. Thus, the results of elemental analysis were recognized as a rough estimation.
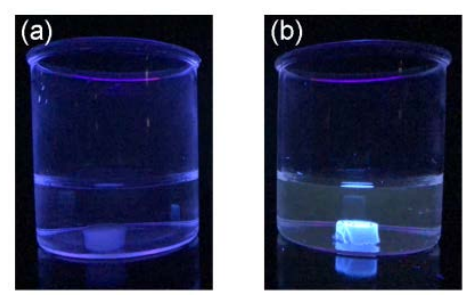

Fig. 4 Photographs of immersed gels under ultraviolet light (365 nm): (a) in water; (b) in aqueous TNS $(20 \mu \mathrm{M})$ solution.

The observed stoichiometry suggests that there are many unoccupied $\beta$-CyD moieties in the gel. To confirm the existence of unoccupied $\beta$-CyD, we employed a fluorometric experiment using TNS that exhibits strong fluorescence when included in the $\beta$-CyD cavity [19]. Fig. 4 (b) shows a bright gel 
in the presence of TNS, confirming the existence of the inclusion complex between the $\beta$-CyD moiety and TNS.

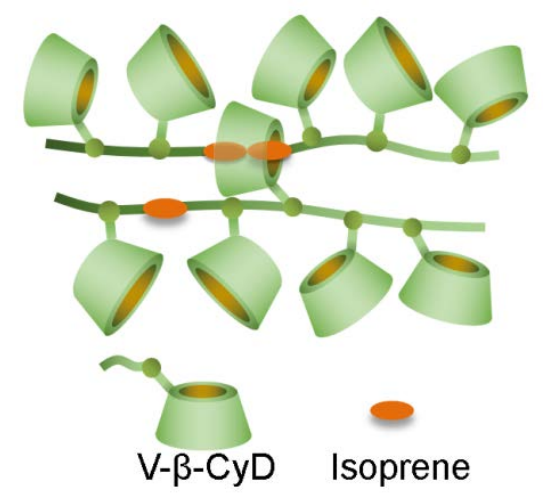

Fig. 5 Proposed structure of the gel composed of V- $\beta-C y D$ and isoprene.

From these investigations, we produced a proposed structure of the gel, illustrated in Fig. 5, reflecting the stoichiometry of V- $\beta$-CyD and isoprene (1:0.3) and the depth of $\beta$-CyD cavity, which can cover 1.5 isoprene monomer units.

\section{Sugar response of the gel containing phenylboronic acid}

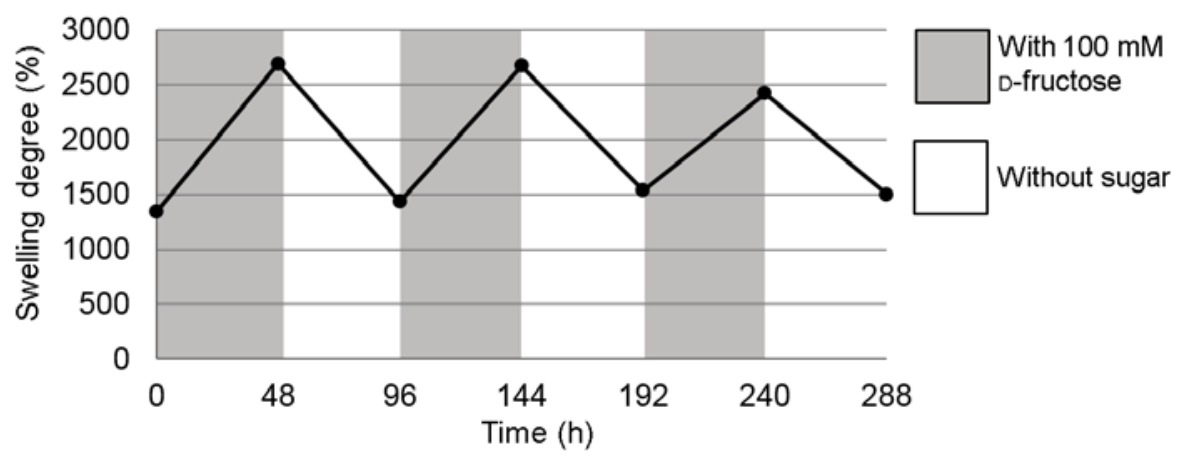

Fig. 6 Sugar response of the gel composed of V- $\beta$-CyD, isoprene, and 4-vinylphenylboronic acid in buffer solution (10 mM HEPES, pH 7.4).

A gel containing PBA was prepared using 4-vinylphenylboronic acid. We tried to investigate the composition of the gel containing PBA with the solution state NMR which was used for the gel not containing PBA. To prepare a sample for the solution state NMR, the gel should dissolve in $1 \mathrm{M}$ $\mathrm{NaOH}$ aqueous solution at $60^{\circ} \mathrm{C}$; however, the gel containing PBA did not completely dissolve, and a small amount of floating object was found in the solution. Thus, it was difficult to estimate the molar ratio with the solution state NMR.

We applied the gel containing PBA to the elemental analysis, although it provides a rough estimation. The found values of the gel containing PBA were C 43.96, H 6.45, and N 2.08\%, 
which are close to the values of the first gel not containing PBA (C 43.62, H 6.75, and N $1.52 \%$ ), which suggests a certain amount of isoprene was lost in the polymerization process.

To confirm the existence of PBA in the gel, we investigate the sugar response of the gel using swelling tests. The gel was immersed in a buffer solution (10 mM HEPES, $\mathrm{pH} 7.4$ ) for $48 \mathrm{~h}$, and its weight was measured (Fig. 6). The gel was subsequently resuspended in $100 \mathrm{mM}$ D-fructose, which was used as a model sugar due to its high affinity for phenylboronic acid [20]. After immersion in Dfructose solution, the gel showed further swelling. This sugar-induced swelling is due to an increase of charged species in the gel. Phenylboronic acid is a Lewis acid and interacts with hydroxide ions. In the presence of sugar, the phenylboronic acid moiety reacts with the sugar hydroxyl group to form a cyclic ester. The sugar-bound form tends to react with hydroxide ions to become an anionic charged species. This phenomenon is known as an apparent decrease in $\mathrm{p} K_{\mathrm{a}}$ of phenylboronic acid by sugar [20]. In the gel, sugar induces an apparent decrease in $\mathrm{p} K_{\mathrm{a}}$ of the phenylboronic acid moiety, resulting in an increase of charged species in the gel. Therefore, the charged copolymer spreads in water, leading to the swelling of the gels.

The sugar-induced swollen gel was immersed in the buffer solution without sugar. After $48 \mathrm{~h}$, the swelling degree returned to the original value. The solution replacements were repeated, and the corresponding swelling and shrinking events were repeatedly observed. The swelling value in the buffer solution tended to remain constant with repetition, suggesting that the gel did not disintegrate and dissolve. In contrast, the swelling values observed in the D-fructose solution decreased slightly with repetition, for reasons that are not clear. In future work, detailed investigations are necessary to clarify the mechanical features of the topological gel.

\section{Conclusion}

We have successfully prepared a topological gel by copolymerization of V- $\beta$-CyD and isoprene in a single step. V- $\beta$-CyD and isoprene are essential for gelation, which was confirmed through comparative experiments. In addition, coexistence of a guest for $\beta$-CyD inhibited the gelation, confirming that the inclusion process is necessary for gelation. The prepared gel swelled for the solvent deemed good for $\beta$-CyD due to a relatively high content of the $\beta$-CyD moiety. Fluorometry using TNS showed that the appended $\beta$-CyD moiety present in the gel possesses inclusion ability. As for the application of the single-step gel preparation, we introduced a sugar response property by including 4-vinylphenylboronic acid within the gel. This success encourages us to further study a wide variety of functional vinyl monomers for single-step preparation of topological gels with the figure-of-six cross-linker.

\section{References}

1. Alvarez-Lorenzo, C., García-González, C.A., Concheiro, A.: Cyclodextrins as versatile building 
blocks for regenerative medicine. J. Control. Release. 268, 269-281 (2017).

2. Arima, H., Motoyama, K., Higashi, T.: Potential use of cyclodextrins as drug carriers and active pharmaceutical ingredients. Chem. Pharm. Bull. 65, 341-348 (2017).

3. Jansook, P., Ogawa, N., Loftsson, T.: Cyclodextrins: structure, physicochemical properties and pharmaceutical applications. Int. J. Pharm. 535, 272-284 (2018).

4. Wenz, G., Han, B.H., Müller, A.: Cyclodextrin rotaxanes and polyrotaxanes. Chem. Rev. 106, 782-817 (2006).

5. Harada, A., Hashidzume, A., Yamaguchi, H., Takashima, Y.: Polymeric rotaxanes. Chem. Rev. 109, 5974-6023 (2009).

6. Okumura, Y., Ito, K.: The polyrotaxane gel: A topological gel by figure-of-eight cross-links. Adv. Mater. 13, 485-487 (2001).

7. Noda, Y., Hayashi, Y., Ito, K.: From topological gels to slide-ring materials. J. Appl. Polym. Sci. 131, 1-9 (2014).

8. Ito, K.: Slide-ring materials using cyclodextrin. Chem. Pharm. Bull. 65, 326-329 (2017).

9. Kali, G., Eisenbarth, H., Wenz, G.: One pot synthesis of a polyisoprene polyrotaxane and conversion to a slide-ring gel. Macromol. Rapid Commun. 37, 67-72 (2016).

10. Hilschmann, J., Kali, G., Wenz, G.: Rotaxanation of polyisoprene to render it soluble in water. Macromolecules. 50, 1312-1318 (2017).

11. Hilschmann, J., Wenz, G., Kali, G.: One-pot synthesis of block-copolyrotaxanes through controlled rotaxa-polymerization. Beilstein J. Org. Chem. 13, 1310-1315 (2017).

12. Michishita, T., Takashima, Y., Harada, A.: Complex formation between polyisoprene and cyclodextrins. Macromol. Rapid Commun. 25, 1159-1162 (2004).

13. Ravaine, V., Ancla, C., Catargi, B.: Chemically controlled closed-loop insulin delivery. J. Control. Release. 132, 2-11 (2008).

14. Seki, T., Abe, K., Nakamura, K., Egawa, Y., Miki, R., Juni, K., Seki, T.: Sugar-responsive pseudopolyrotaxanes and their application in sugar-induced release of PEGylated insulin. J. Incl. Phenom. Macrocycl. Chem. 82, 417-424 (2015).

15. Seki, T., Abe, K., Egawa, Y., Miki, R., Juni, K., Seki, T.: A pseudopolyrotaxane for glucoseresponsive insulin release: The effect of binding ability and spatial arrangement of phenylboronic acid group. Mol. Pharm. 13, 3807-3815 (2016).

16. Wenz, G.: Inclusion of adamantan derivatives. Macromol. Rapid Commun. 17, 731-736 (1996).

17. Joseph, R., Zhang, S., Ford, W.T.: Structure and dynamics of a colloidal silica-poly(methyl methacrylate) composite by 13C and 29Si MAS NMR spectroscopy. Macromolecules. 29, 13051312 (1996).

18. Larsen, F.H., Rasmussen, T., Pedersen, W.B., Nielsen, N.C., Jakobsen, H.J.: Observation of immobile regions in natural rubber at ambient temperature by solid-state 13C CP/MAS NMR 
spectroscopy. Polymer. 40, $7013-7017$ (1999).

19. Ito, A., Ooya, T., Yui, N.: Preparation of polypseudorotaxane consisting of fluorescent molecule-modified $\beta$-cyclodextrins and biotin-terminated poly(propylene glycol) with high yield. J. Incl. Phenom. Macrocycl. Chem. 57, 233-236 (2007).

20. Springsteen, G., Wang, B.: A detailed examination of boronic acid-diol complexation. Tetrahedron. 58, 5291-5300 (2002). 


\section{Supporting Information}

\section{Single-step preparation of topological gels using vinyl-modified $\beta$ - cyclodextrin as a figure-of-six cross-linker}

Yuki Kobayashi, ${ }^{\text {a } Y u ~ K o j i m a, ~}{ }^{\text {a }}$ Ryotaro Miki, ${ }^{\text {a }}$ Toshinobu Seki, ${ }^{\text {a }}$ Takashi Fujihara, ${ }^{\text {b }}$ Yoshihiro Ishimaru, ${ }^{\text {c }}$

Yuya Egawa*a

a. Faculty of Pharmacy and Pharmaceutical Sciences, Josai University, 1-1 Keyakidai, Sakado, Saitama 350-0295, Japan

b. Research and Development Bureau, Comprehensive Analysis Center for Science, Saitama University, Shimo-ohkubo 255, Sakura-ku, Saitama, Saitama 338-8570, Japan

c. Division of Material Science, Graduate School of Science and Engineering, Saitama University, 255 Shimo-ohkubo, Sakura-ku, Saitama, Saitama, 338-8570, Japan

\section{Contents}

${ }^{1} \mathrm{H}$ NMR spectrum of V- $\beta-\mathrm{CyD}$

Mass spectrum of V- $\beta-\mathrm{CyD}$

Solid-state ${ }^{13} \mathrm{C}$ CP/MAS NMR spectrum of V- $\beta$-CyD

Solid-state ${ }^{13} \mathrm{C}$ CP/MAS NMR spectrum of the ground gel

${ }^{1} \mathrm{H}$ NMR spectrum of the dissolved gel 


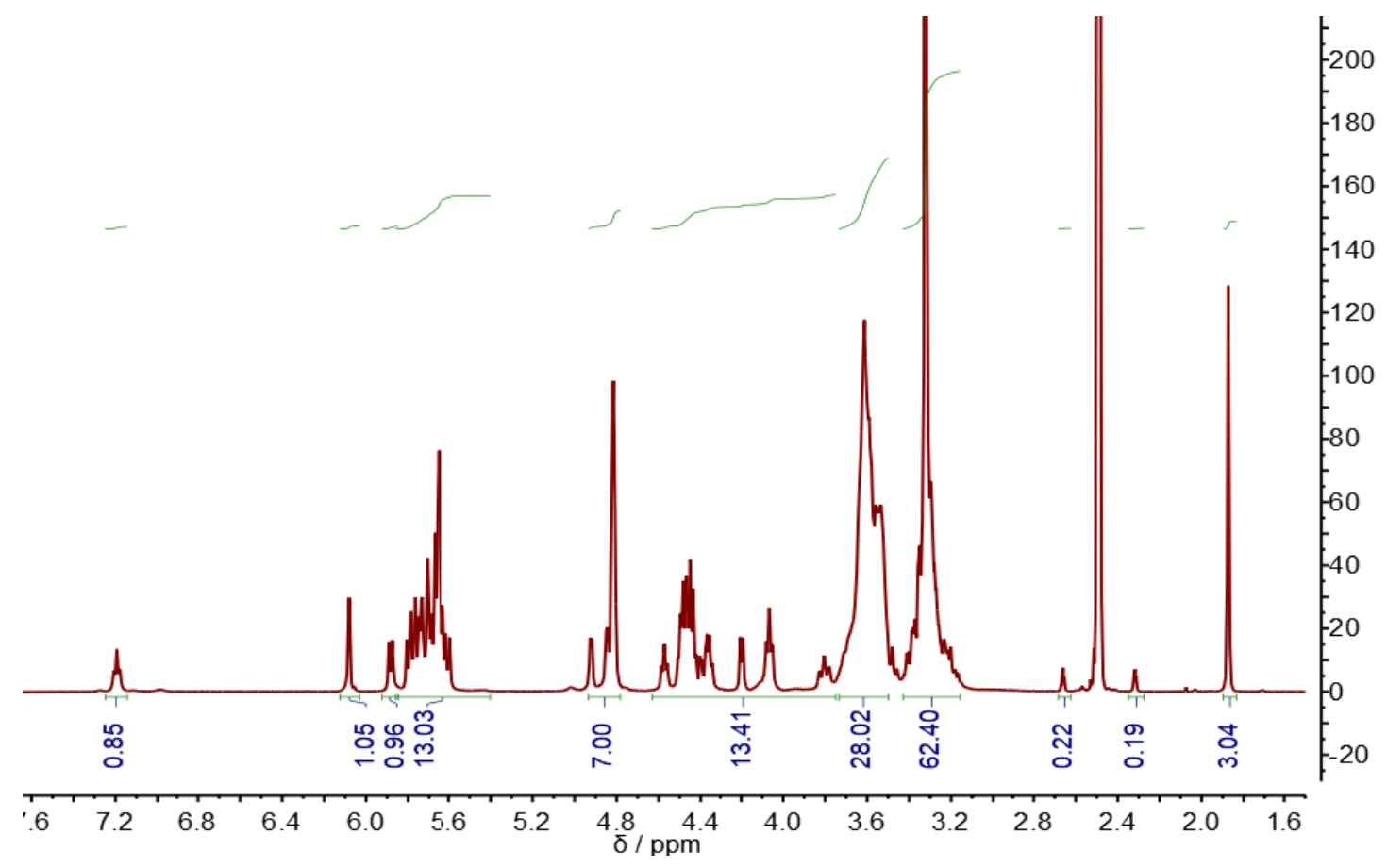

Fig. S1 ${ }^{1} \mathrm{H}$ NMR spectrum of V- $\beta$-CyD in DMSO- $d_{6}$.

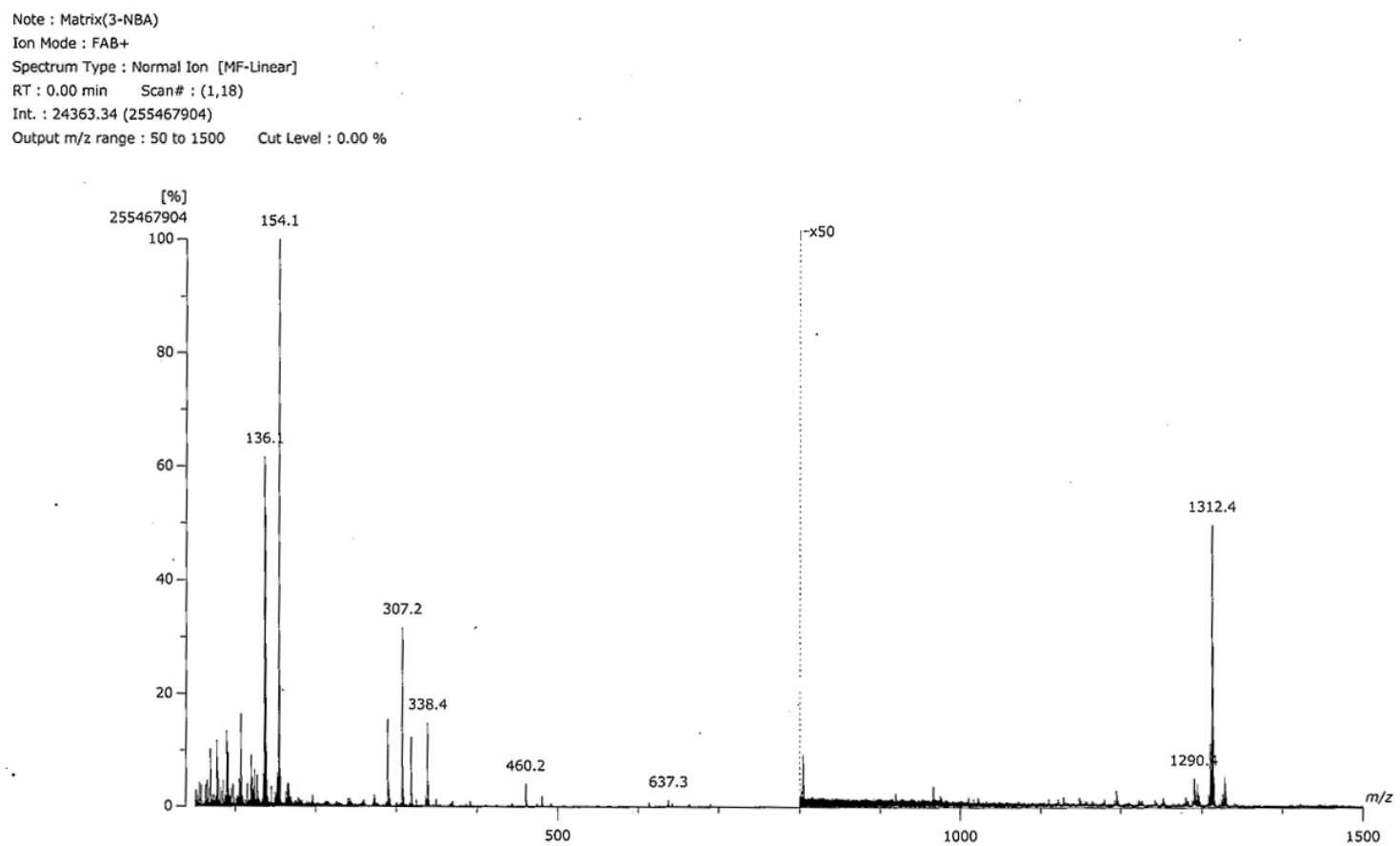

Fig. S2 Mass spectrum of V- $\beta-C y D(F A B$, positive mode, matrix: 3-NBA) m/z: 1312.4 (expected $\mathrm{m} / \mathrm{z}$ of $[\mathrm{M}+\mathrm{Na}]^{+}:$1312.4). 


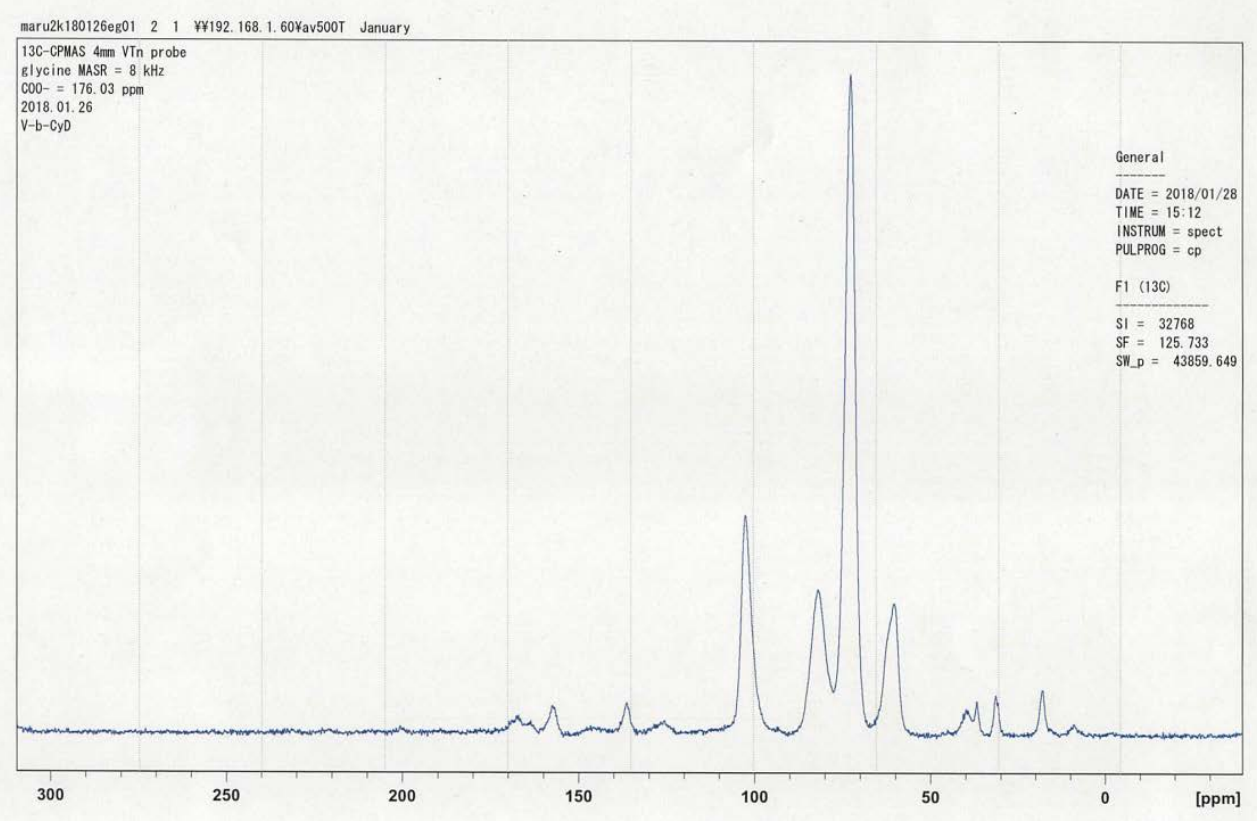

Fig. S3 Solid-state ${ }^{13} \mathrm{C}$ CP/MAS NMR spectrum of V- $\beta$-CyD.

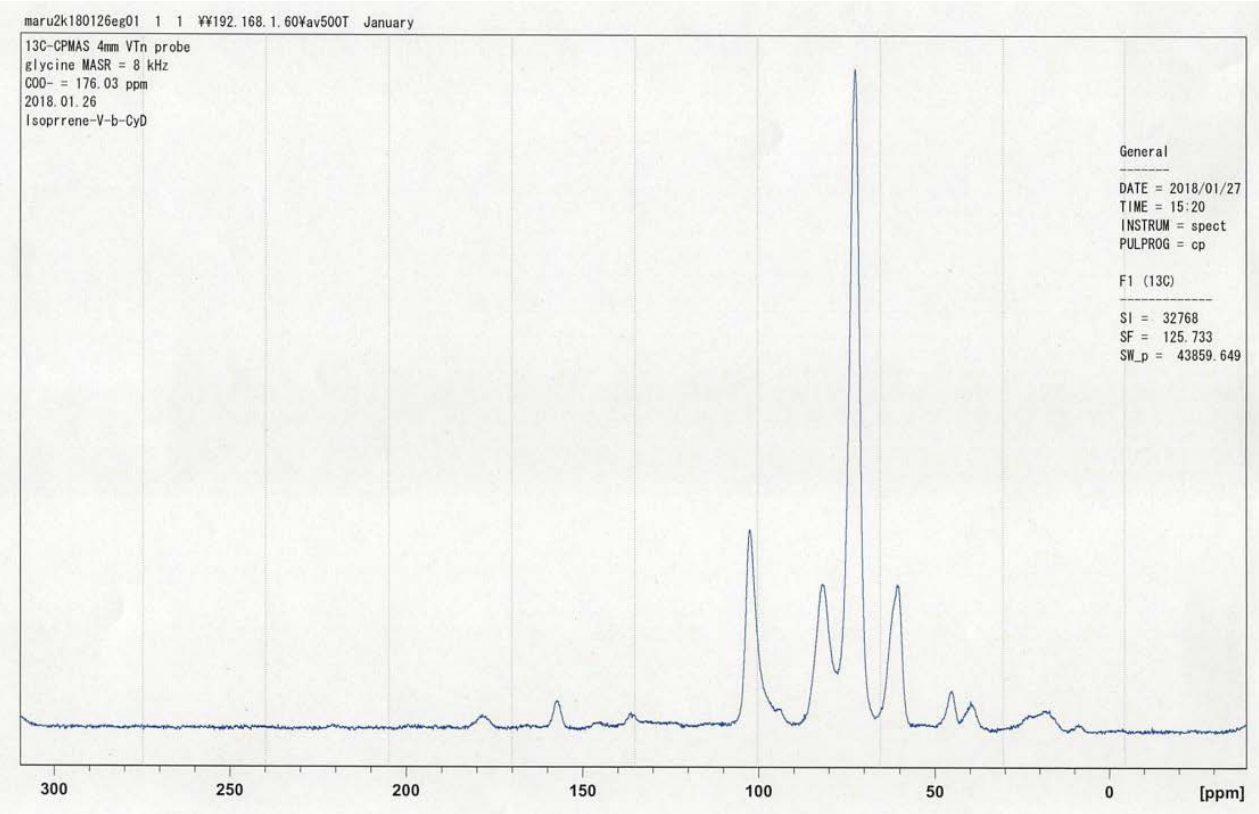

Fig. S4 Solid-state ${ }^{13} \mathrm{C}$ CP/MAS NMR spectrum of the ground gel. 


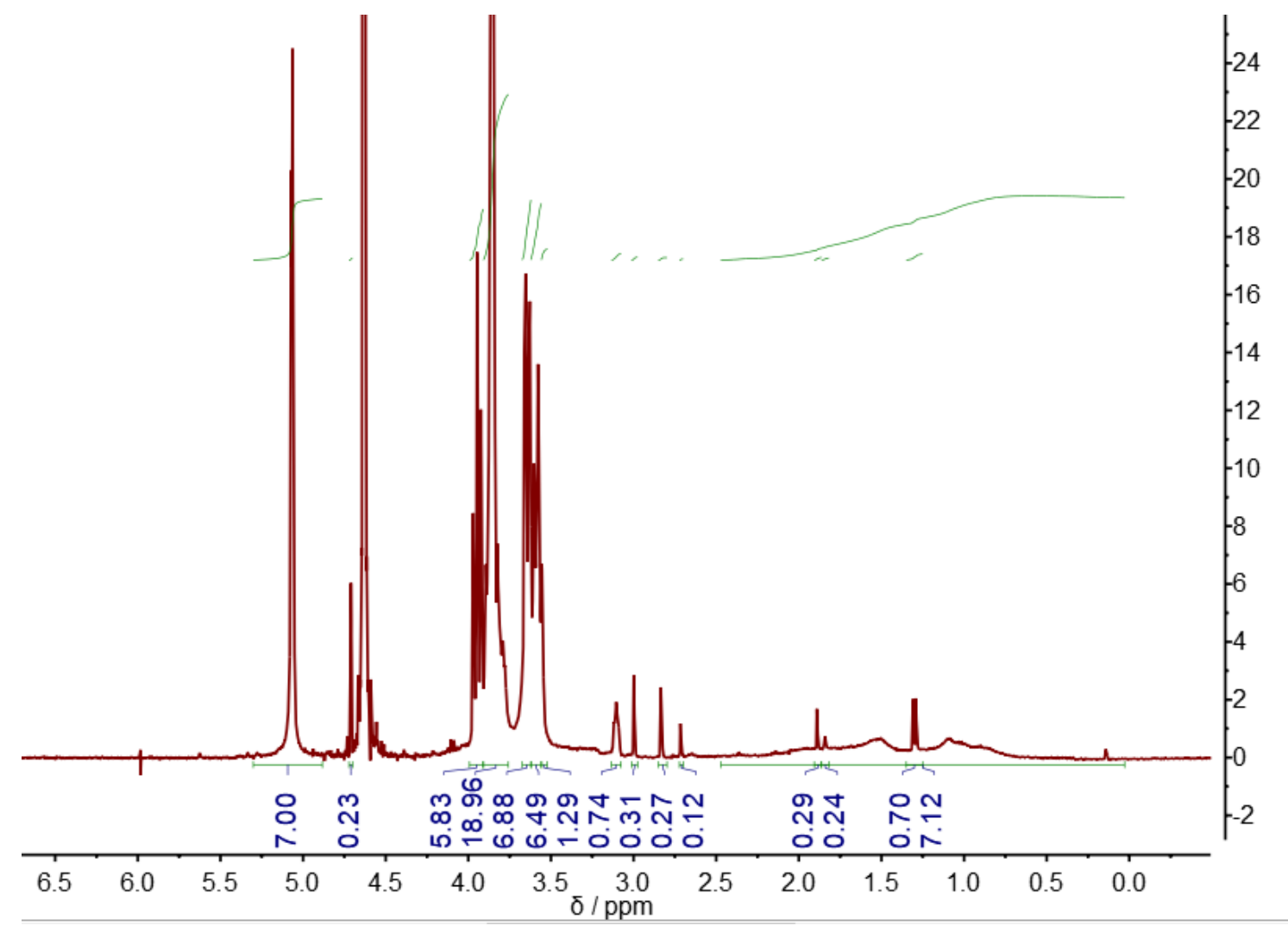

Fig. S5 ${ }^{1} \mathrm{H}$ NMR spectrum of the dissolved gel in $\mathrm{D}_{2} \mathrm{O}$. 